\title{
Beam Acceleration in the LBL 88-Inch Cyclotron with Injection from the AECR Source*
}

\author{
D.J. Clark, C.M. Lyneis and Zuqi Xie \\ Nuclear Science Division, Lawrence Berkeley Laboratory, University of California \\ 1 Cyclotron Road, Berkeley, CA 94720, U.S.A.
}

\begin{abstract}
DISCLATMER
This report was prepared as an account of work sponsored by an agency of the United Staies Government. Neither the United States Government nor any agency thereof, nor any of their employeses, makes any warranty, express or implied, or assumes any legal liability or responsibility for the accuracy, completeness, or usefulness of any information, apparatus, product, or process disclosed, or represents that its use would not infringe privately owned rights. Reference herein to any specific commercial product, process, or service by trade name, trademark, manufacturer, or otherwice does not necessarily constitute or imply its endorsernent, rocommendation, or favoring by the United States Government or any agency thereor. The views and opinions of authors expressed herein do not necessarily state or reflect those of the United States Government or any agency thereor.
\end{abstract}

*This work was supported by the Director, Office of Energy Research, Division of Nuclear Physics of the Office of High Energy and Nuclear Physics of the U.S. Department of Energy under Contract DE- ACO3-76SF00098. 


\title{
Beam Acceleration in the LBL 88-Inch Cyclotron with Injection from the AECR Source*
}

\author{
D.J. Clark, C.M. Lyneis and Zuqi Xie \\ Nuclear Science Division, Lawrence Berkeley Laboratory, University of California \\ I Cyclotron Road, Berkeley, CA 94720, U.S.A.
}

\begin{abstract}
The new Advanced ECR (AECR) source is being developed [1] for the 88-Inch Cyclotron at Lawrence Berkeley Laboratory. It operates at $14.5 \mathrm{GHz}$, compared to 6.4 $\mathrm{GHz}$ for the present LBL ECR source [2]. An electron gun [3] injects electrons into the plasma chamber to increase the production of high charge state ions. The first AECR beams were injected into the cyclotron in June of 1990 and since then a variety of ion species from the AECR have been accelerated, including beams from oxygen at 32 $\mathrm{MeV} / \mathrm{u}$ to bismuth at $4.6 \mathrm{MeV} / \mathrm{u}$. A Xe $\mathrm{Xe}^{32+}$ beam of $1054 \mathrm{MeV}$ or $8 \mathrm{MeV} / \mathrm{u}$ was accelerated.
\end{abstract}

\section{INTRODUCTION}

The system used to inject beams from the ECR sources into the cyclotron is shown in Fig. 1. Either the LBL ECR or the AECR can be used to inject the cyclotron. There are several advantages of adding the $A E C R$ source. The new AECR source operates at $14.5 \mathrm{GHz}$, compared to $6.4 \mathrm{GHz}$ for the $\mathrm{LBL} E C R$, to take advantage of the demonstration by Geller's group in Grenoble that both higher intensities and higher charge states could be produced by operating at higher frequency. A higher charge state, $Q$, produces higher cyclotron energy as $Q^{2}$. Also the flexibility of the system is increased by having two sources and analyzing systems, because one source can be used for cyclotron injection while the other is used for development, maintenance or atomic physics experiments. The LBL ECR source has injected beams for regular operation since 1985. The AECR source was completed in Dec. 1989 and is now undergoing testing. This paper describes the AECR source, its high charge state beam performance with an electron gun, the injection system into the cyclotron and the acceleration of beams from the AECR through the cyclotron. 


\section{THE AECR SOURCE}

Figure 2 illustrates the design of the AECR. A single $14.5 \mathrm{GHz} 2.5 \mathrm{~kW}$ klystron supplies microwave power to the source. The independent coils make it easy to vary the axial magnetic field. An iron yoke around the coils increases the axial field at each end while the iron plates between coils 2 and 3 reduce the axial field in the center to achieve the required mirror satio. Pumping for the plasma chamber and extraction regions is provided by a $240 \mathrm{l} / \mathrm{s}$ and a $500 \mathrm{l} / \mathrm{s}$ turbomolecular pumps, respectively. In May 1990, we developed an electron gun [3], which injects cold electrons on axis into the plasma. The electron gun is shown at the left side of Fig. 2. As shown in Table I, the AECR can produce much higher charge state ion beams than the LBL ECR, and the maximum ion currents are much higher than those from the LBL ECR for the same charge state ion beams. The best results to date were obtained with electron currents between 20 and $100 \mathrm{~mA}$ at bias voltages between 50 and $150 \mathrm{~V}$. With the electron gun, the optimum microwave power and total extracted currents were typically $2 \mathrm{~kW}$ and 2 to $3 \mathrm{~m} A$, respectively. The lifetime of the first $\mathrm{LaB}_{6}$ cathode was about 600 homrs. To improve the operational stability of the AECR source a new se $x$ tupole magnet is bein built, with stronger field at the chamber walls.

\section{THE INJECTION SYSTEM}

The LBL ECR souice uses 10 meters of horizontal beamline for injection, Fig. 1. The AECR is placed opposite the LBL ECR, and uses 7 meters of horizontal beam line. The two horizontal beamlines meet in a common 4 meter long vertical transport line to the cyclotron. Magnetic rather than electrostatic bending, focusing and steering elements were chosen because of better space charge neutralization, fewer vacuum penetrations and better long term reliability. Focusing is done with quadrupoles and Glaser lenses (magnetic solenoids with iron return yokes). Coils mounted on the beam pipe provide steering. To minimize beam steering due to the stray field of the cyclotron, nickel plated magnetic steel beam pipes were used where possible.

The AECR and LBL ECR sources use the same design for analyzing systems. A Glaser focuses the source beam at the analyzing system entrance slits. The beam is then analyzed and focused by the iritial 90 degree magnet. The resolution is $1 / 100$ in mass for full transmission, and 1/200 with narrowet slit settings. The new section of horizontal beamline for the AECR, from the analyzing magnet to the vertical line, uses a Glaser and a quadrupole doublet to match the beam through the 90 degree bend into the 
vertical line. The sections of the beamline between the source analyzing magnets and the vertical axial injection line are commonly powered for the LBLECR and the AECR beamlines, which not only reduces the cost but aisu simplifies the control system.

The vacuum system uses cryo-pumps and turbo-pumps and all metal seals. The typical beam line pressure is $5 \times 10^{-8}$ Torr which is sufficiently low so that beam loss due to charge exchange with residual gas is negligible.

Beam diagnostics along the injection beam line consist of fixed four jaw collimators with beam readouts before each set of lenses, where the beam is large. Beam current con be read on several Faraday cups along the line.

A gridded buncher is placed $2.1 \mathrm{~m}$ above the cyclotron midplane. At the cyclotron center the beam from the injection system is bent through 90 degrees by a gridded electrostatic mirror with a transmission of $90 \%$. Beam current can be read on the mirror with the voltage off, a useful diagnostic for low level beams.

In our non-scaling mode of operation the requirement for beam centering is that the dee voltage should be approximately 5 times the injection voltage. The usual operating values are $10 \mathrm{kV}$ for the injection voltage and $50 \mathrm{kV}$ for the dee voltage. The advantage of operating in this non-scaling mode is that the dee voltage can be operated near its maximum for all beams, giving the minimum number of particle turns and thus high center region acceptance and low beam loss due to stripping during acceleration. Also, keeping the injection voltage high reduces the emittance in the transport line to increase transmission.

\section{PERFORMANCE OF THE 88-INCH CYCLOTRON WITH THE AECR}

The cyclotron accelerates protons to $55 \mathrm{MeV}$, ions with $\mathrm{Q} / \mathrm{A}=1 / 2$ to $32.5 \mathrm{MeV} / \mathrm{u}$, and heavier beams to $E / A=K Q^{2} / A^{2}$, where the maximum $K=140$. The transmission from source to external beam has been typically 3-20\% with the LBL ECR source. The loss of beam due to charge exchange during acceleration ranges from $10 \%$ for highly stripped light ions to over $50 \%$ for heavy ions such as xenon.

With the higher charge state ion beams produced by the AECR, the performance of the 88-Inch Cyclotron has been greatly enhanced. The AECR source can inject beams of higher intensity and higher charge state than those available with the LBL ECR source. Table II shows the ion beams injected from the AECR and accelerated by the 88-Inch Cyclotron. The "BS" column indicates the first beam stop for external beam. A wide variety of ions at high charge states has been accelerated, including 
$\mathrm{Ar}^{16+}, \mathrm{Kr}^{25+}, \mathrm{Xe}^{32+}$ and $\mathrm{Bi}^{38+}$. The low temperature oven was used for bismuth production.

These high charge state ions have a large electron pick-up cross-section at the low energy region in the center of the cyclotron. Although the pressure is $1-2 \times 10^{-6}$ torr near the vacuum tank outer wall, it is higher in the center region and there is still significant beam loss during acceleration for these beams. For the xenon beams of Table II the beam loss is a factor of $2-5$, for pressures in the above range. For the bismuth beams the loss is a factor of 5-40. So a better vacuum is very important for higher transmission of these beams.

The injection efficiency has been similar to that with the LBL ECR, with about $10 \%$ transmission from source to external beam for typical first harmonic beams. The $160 \mathrm{MeV}$ oxygen beam of Table II is a typical high intensity beam, with $6 \mu \mathrm{A}$ on the beam stop. The maximum $\mathrm{K}$ of 140 was used for most of the beams to study the performance at maximum energy. The beams use first harmonic acceleration, except for those below $6 \mathrm{MeV} / \mathrm{u}$, which use third harmonic. Fig. 3 shows the best performance of the cyclotron with the AECR and the performance with the LBL ECR.

A useful technique for rapid charge state and energy variation [4] has been used for runs with both the LBL ECR and AECR sources. The charge state from the source is changed, and the injection voltage is also changed to keep it proportional to charge state, so the injection line magnet settings are unchanged. The cyclotron $\mathrm{K}$ is constant, which eliminates the settling time of the main magnet. This technique was useful for changing charge states of the high charge stare beams in Table II.

\section{REFERENCES}

[1] C. M. Lyneis, Zuqi Xie, D. J. Clark, R. S. Lam and S. A. Lundgren, Proc. 10th Int'l Workshop on ECR Ion Sources, Knoxville, Tenn., Nov. 1990.

[2] D. J. Clark and C. M. Lyneis, Proc. 12th Int'l Conf. on Cyclotrons and Their Applications, Berlii, FRG, May 1989, LBL-26401.

[3] Zuqi Xie, C. M. Lyneis, R. S. Lam and S. A. Lundgren, Rev. Sci. Instr. 62 (3), Mar. 1991.

[4] D. J. Clark and G. J. Wozniak, Nucl. Instr. \& Meth., A295 (1990) p.34.

*This work was supported by the Director, Office of Energy Research, Division of Nuclear Physics of the Office of High Energy and Nuclear Physics of the U.S. Department of Energy under Contract DE- ACO3-76SF00098. 
Table I. Comparison of ion currents in e $\mu \mathrm{A}$ from the AECR and $\mathrm{LBL}$ ECR sources. All measurements reported were done with a source extraction aperture of $8 \mathrm{~mm}$ diameter and $10 \mathrm{kV}$ of beam acceleration.

\begin{tabular}{|l|c|l|}
\hline ION & $\begin{array}{c}\text { AECR } \\
\text { with E. Gun }\end{array}$ & LBL ECR \\
\hline $\mathrm{O}^{6+}$ & 475 & 90 \\
\hline $\mathrm{O}^{7+}$ & 131 & 20 \\
\hline $\mathrm{O}^{8+}$ & $\sim 13$ & $\sim 0.95$ \\
\hline $\mathrm{Ar}^{11+}$ & 141 & 18 \\
\hline $\mathrm{Ar}^{13+}$ & 34 & 7 \\
\hline $\mathrm{Ar}^{16+}$ & 1.4 & 0.03 \\
\hline $\mathrm{Kr}^{19+}$ & $36^{*}$ & 2 \\
\hline $\mathrm{Kr}^{22+}$ & $10^{*}$ & 0.1 \\
\hline $\mathrm{Kr}^{25+}$ & $2.2^{*}$ & \\
\hline $\mathrm{Kr}^{28+}$ & $0.25^{*}$ & \\
\hline $\mathrm{Xe}^{24+}$ & $30^{*}$ & 2 \\
\hline $\mathrm{Xe}^{27+}$ & $12^{*}$ & 0.3 \\
\hline $\mathrm{Xe}^{31+}$ & $1^{*}$ & \\
\hline $\mathrm{Bi}^{28+}$ & 6 & 2.5 \\
\hline $\mathrm{Bi}^{31+}$ & 4.5 & 0.56 \\
\hline $\mathrm{Bi}^{34+}$ & 1.5 & 0.05 \\
\hline $\mathrm{Bi}^{38+}$ & 0.2 & \\
\hline
\end{tabular}

* Isotopically enriched gas used. 
Table II. AECR Beams Accelerated by the 88-Inch Cyclotron.

\begin{tabular}{lcrccc}
\multicolumn{3}{c}{ Charge } & \multicolumn{3}{c}{$\mathrm{E} / \mathrm{A}$} \\
Ion & State & $\mathrm{K}$ & $\mathrm{E}(\mathrm{MeV})$ & $(\mathrm{MeV} / \mathrm{u})$ & $\mathrm{BS}(\mathrm{nA})$ \\
$16 \mathrm{O}$ & 6 & 71 & 160 & 10 & 6200 \\
160 & 8 & 130 & 520 & 32 & 200 \\
$20 \mathrm{Ne}$ & 10 & 130 & 650 & 32 & 90 \\
$40 \mathrm{Ar}$ & 14 & 140 & 686 & 17 & 320 \\
${ }^{40} \mathrm{Ar}$ & 16 & 140 & 896 & 22 & 30 \\
$86 \mathrm{Kr}$ & 23 & 140 & 861 & 10 & 60 \\
$86 \mathrm{Kr}$ & 25 & 140 & 1017 & 12 & 8 \\
$136 \mathrm{Xe}$ & 29 & 140 & 865 & 6.4 & 30 \\
$136 \mathrm{Xe}$ & 30 & 140 & 926 & 6.8 & 20 \\
$136 \mathrm{Xe}$ & 31 & 140 & 990 & 7.3 & 8 \\
$136 \mathrm{Xe}$ & 32 & 140 & 1054 & 7.8 & 3 \\
$209 \mathrm{Bi}$ & 35 & 138 & 809 & 3.9 & 1.4 \\
$209 \mathrm{Bi}$ & 36 & 138 & 856 & 4.1 & 1.1 \\
$209 \mathrm{Bi}$ & 37 & 138 & 904 & 4.3 & 0.3 \\
$209 \mathrm{Bi}$ & 38 & 138 & 954 & 4.6 & 0.1 \\
\hline
\end{tabular}




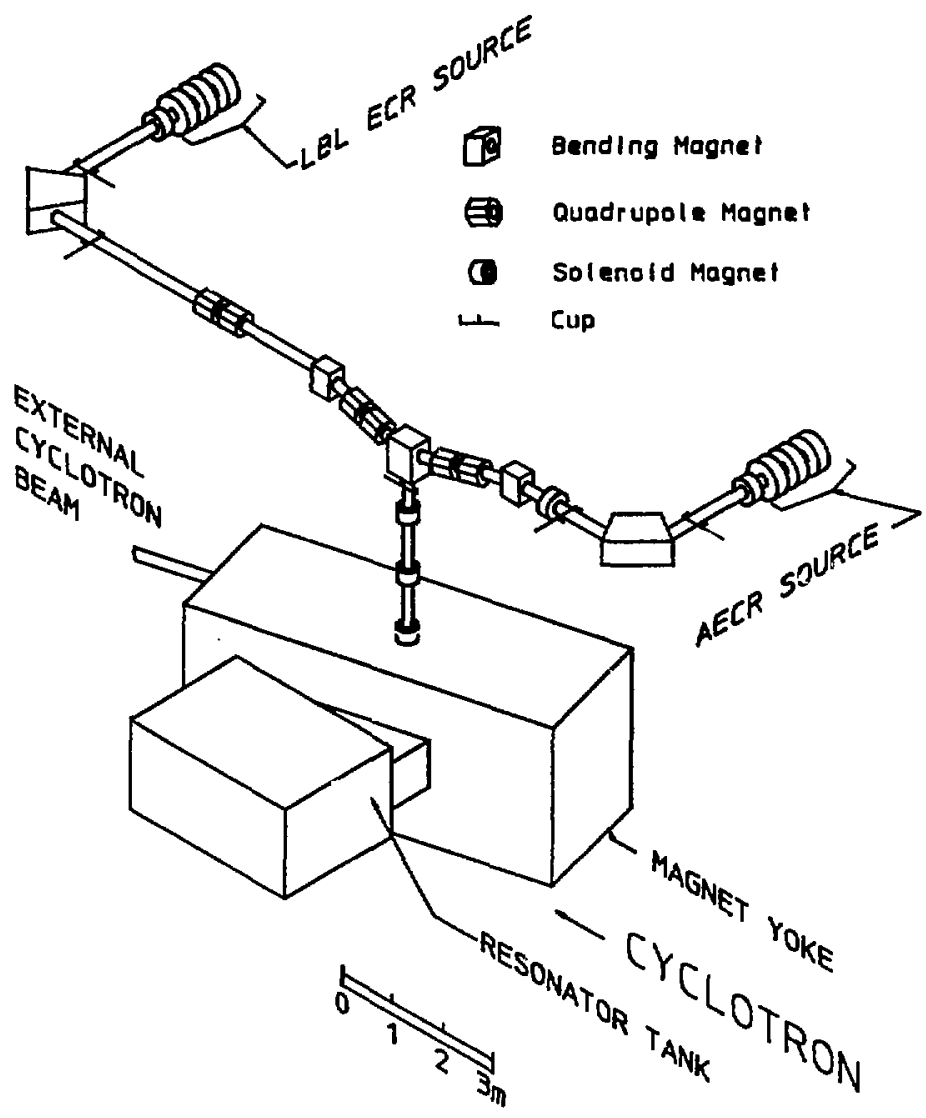

Fig. 1. Schematic view of the injection beam transport lines for the 88-Inch Cyclotron, from the LBL ECR and the AECR sources. Either of these two ion sources can inject beams into the cyclotron. XBL 915-1071. 


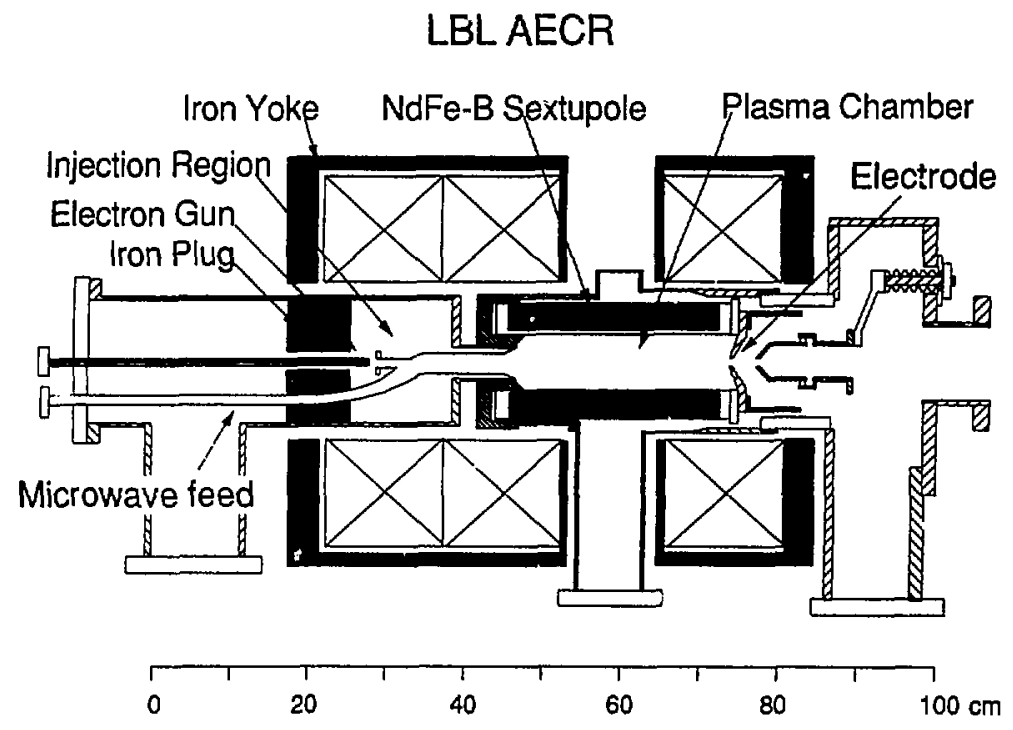

Fig. 2. Schematic drawing of the AECR. The axial magnetic field is produced by copper coils in an iron yoke. The iron plug on the injection side was added to increase the axial magnetic fied. Electrons from $\mathrm{L}_{\mathrm{LB}} 6$ filament flow along the axial magnetic field lines into the plasma chamber. XBL 915-1072. 


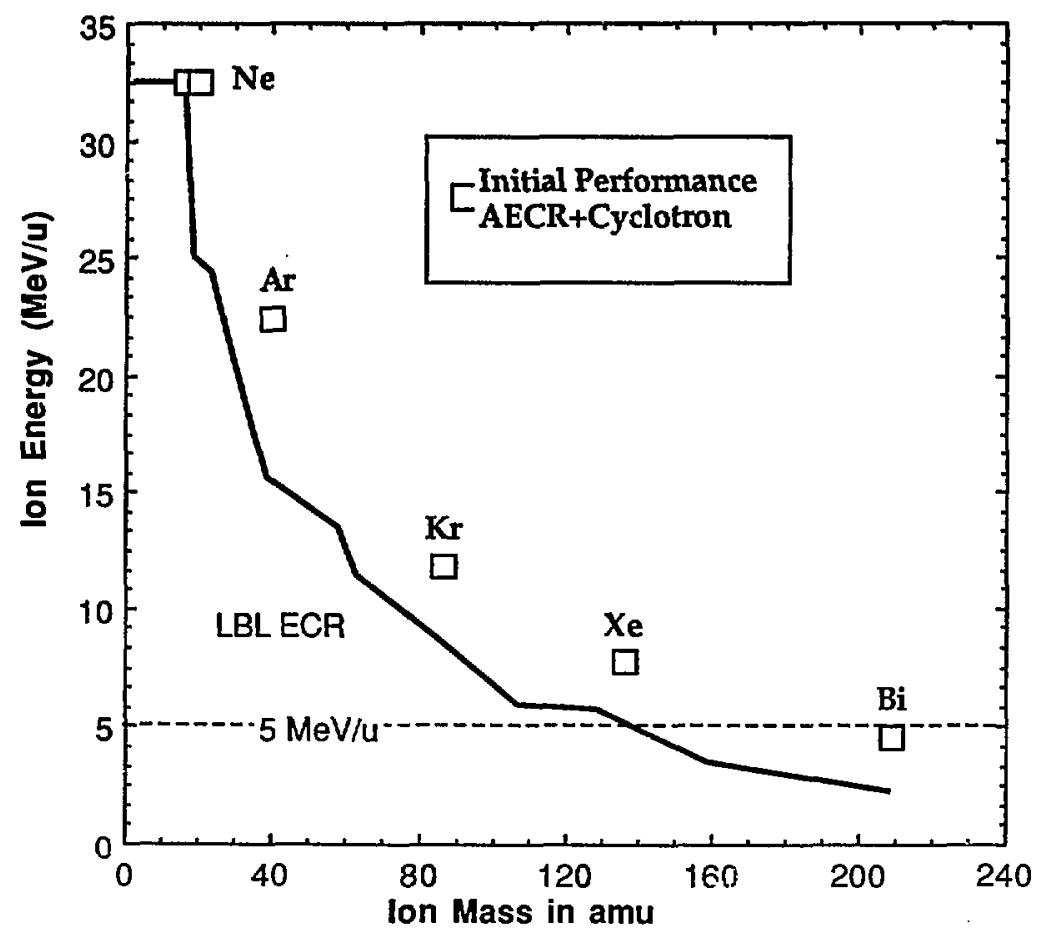

Fig. 3. The best performance of beams accelerated by the LBL ECR and the AECR sources in the 88-Inch Cyclotron. XBL 915-1073. 